\title{
Distribution of toxin genes among different spa types and phage types of animal Staphylococcus aureus
}

\author{
Katarzyna Garbacz $^{1} \cdot$ Lidia Piechowicz $^{1}$. Aneta Mroczkowska ${ }^{2}$
}

Received: 28 January 2015 / Revised: 8 June 2015 / Accepted: 14 June 2015 / Published online: 25 June 2015

(C) The Author(s) 2015. This article is published with open access at Springerlink.com

\begin{abstract}
We analyzed distribution of toxin genes (seaseo, eta, etb, tst, lukS/lukF-PV) among spa types and phage types of 39 Staphylococcus aureus (S. aureus) isolates from healthy and diseased animals. All isolates turned out to be $m e c A$ negative (MSSA). Nine spa types were identified: t144 and t723 (dogs), t084 (dogs and pigs), t5447 (cat), t1491 and t008 (pigs), t002, t127 and t3478 (poultry). Seven phage types were detected, enclosed within four phage groups: I (cat), II (dogs), III (pigs) and mixed group (dogs and pigs). Three poultry spa types proved to be nontypeable by phages. Toxin genes were detected in 33 out of the 39 animal isolates. Our analysis revealed that the incidence of some toxin genes in S. aureus is host specific. Canine isolates $\mathrm{t} 144$ of phage group II harbored exfoliative toxin gene (eta), and porcine isolates type $\mathrm{t} 1491$ representing phage group III showed enterotoxin A gene (sea). The enterotoxin gene cluster $(\mathrm{egcl})$ and enterotoxin gene seh were found in non-typeable isolates from chicken and in one feline isolate type $t 5447$.
\end{abstract}

Keywords Animal S. aureus - spa typing - Phage typing · Toxin genes

Communicated by Erko Stackebrandt.

Katarzyna Garbacz

kasgab@gumed.edu.pl

1 Department of Medical Microbiology, Medical University of Gdansk, 38 Do Studzienki St., 80-227 Gdańsk, Poland

2 Department of Epidemiology and Clinical Microbiology, National Medicines Institute, 30/34 Chełmska St., 00-725 Warsaw, Poland

\section{Introduction}

Although Staphylococcus aureus is mostly a widely spread human pathogen, it can be also isolated from animals (Devriese 1984; Sung et al. 2008). The distribution of specific $S$. aureus strains among hosts of various species is an interesting albeit still poorly understood issue. Although staphylococcal strains vary depending on the host, some types can be isolated from both humans and animals. This was confirmed by recent molecular studies, as well as by previous research based on phage typing (Hasman et al. 2010; Krynski et al. 1981). Phage typing was one of the first methods used to analyze the relatedness of staphylococcal strains. However, nowadays, this method was nearly entirely replaced by genotyping, mostly due to increasing prevalence of strains that are non-typeable by phages. Nevertheless, phage typing can provide valuable information on the prevalence and evolution of certain human and animal S. aureus isolates (Krynski et al. 1981; Vintov and Aarestrup 2003; Vintov et al. 2003). Nowadays, spa typing is the most widely used method for the first-line typing and epidemiological analyses. This method determines the sequence variation of the polymorphic region $X$ of the spa gene for $S$. aureus surface protein A. The diversity of the spa gene, consisting mainly of a number of repeats of $24 \mathrm{bp}$ in length, is attributed to point mutations, as well as to deletions and duplications of the repeats. The $s p a$ typing allows us to characterize and compare strains isolated from various hosts for their phylogenetic relatedness (Ebner et al. 2013; Espinosa-Gongora et al. 2012; Vincze et al. 2013). S. aureus is known to synthesize an array of virulence factors, such as leukocidins, exfoliative toxins and pyrogenic toxins superantigens (PTSAgs). These toxins cause a variety of diseases in humans (Bukowski et al. 2010; Krakauer 2013). S. aureus strains colonizing various 
Table 1 Distribution of spa types, phage types and toxin genes in animal S. aureus

\begin{tabular}{|c|c|c|c|c|c|c|}
\hline Host species & $\begin{array}{l}\text { Number of iso- } \\
\text { lates }(\mathrm{c} / \mathrm{i})\end{array}$ & Spa type & Predicated $S T^{a}$ & Phage type & Phage group & Toxin gene profile \\
\hline Dog & $8(6 / 2)$ & $\mathrm{t} 144$ & $\begin{array}{l}\text { 07-23-12-34-34-12-12-ST15 or ST18 } \\
\text { 23-02-02-12-23 }\end{array}$ & $3 \mathrm{C} / 55 / 71$ & II & eta \\
\hline Dog & $5(0 / 5)$ & $\mathrm{t} 723$ & $11-19-12-34-22-25$ & $\begin{array}{l}\text { 29/52/52A/79/80/81/6/42E } \\
/ 47 / 53 / 54 / 75 / 83 \mathrm{~A} / 84 / 85 \\
/ 88 / 89\end{array}$ & $\mathrm{I}+\mathrm{III}$ & sea \\
\hline Dog & $3(0 / 3)$ & t084 & $\begin{array}{l}\text { 07-23-12-34-34-12-12-ST15 or ST18 } \\
\text { 23-02-12-23 }\end{array}$ & $89 / 29 / 52 / 52 \mathrm{~A} / 84 / 85 / 88 / 89$ & $\mathrm{I}+\mathrm{III}$ & none \\
\hline Cat & $1(0 / 1)$ & $\mathrm{t} 5447$ & $07-02-16-02-25-17-24-$ & $29 / 79 / 81$ & I & $e g c 1^{b}$ \\
\hline Pig & $12(0 / 12)$ & $\mathrm{t} 1491$ & $\begin{array}{l}\text { 07-23-21-17-13-34-34-ST1 } \\
16-34-33-13\end{array}$ & $75 / 84 / 85$ & III & sea \\
\hline Pig & $2(0 / 2)$ & t008 & $\begin{array}{l}\text { 11-19-12-21-17-34-24-ST8 } \\
\quad 34-22-25\end{array}$ & $6 / 42 / 53 / 54$ & III & none \\
\hline Pig & $1(0 / 1)$ & t084 & $\begin{array}{l}\text { 07-23-12-34-34-12-12-ST15 or ST18 } \\
\text { 23-02-12-23 }\end{array}$ & $52 \mathrm{~A} / 53 / 75 / 83 \mathrm{~A} / 84 / 85$ & $\mathrm{I}+\mathrm{III}$ & none \\
\hline Chicken & $3(0 / 3)$ & $\mathrm{t} 002$ & $\begin{array}{l}\text { 26-23-17-34-17-20-17-ST5 } \\
12-17-16\end{array}$ & NT & NT & $e g c 1^{b}$ \\
\hline Chicken & $2(0 / 2)$ & $\mathrm{t} 127$ & 07-23-21-16-34-33-13 ST1 & NT & NT & sec, seh \\
\hline Chicken & $2(0 / 2)$ & $\mathrm{t} 3478$ & $\begin{array}{l}26-23-17-34-17-20-17-\mathrm{ST} 5 \\
12-17-16-12-17-16\end{array}$ & NT & NT & $e g c 1^{b}$ \\
\hline
\end{tabular}

All isolates, irrespective of their host, turned out to be mecA negative (MSSA)

$c / i$ colonization/infection, $N T$ non-typeable

a ST type retrieved from the Ridom SpaServer

b egcl(seg, sei, sem, sen and seo)

animals and humans may differ in terms of generated toxins (Gomez-Sanz et al. 2013). Synthesis of toxins by animal $S$. aureus isolates constitutes another important and poorly understood issue.

The aim of this study was to determine distribution of toxin genes among spa types and phage types of animal isolates of $S$. aureus.

\section{Results}

A total of $39 S$. aureus isolates were identified, among them 16 canine ( 6 nasal isolates from healthy dogs and 10 isolates from skin lesions), one feline isolate from a cat with conjunctivitis, 15 porcine isolates from pigs with skin lesions and 7 poultry isolates from chicken with arthritis $(n=6)$ and septicemia $(n=1)$.

Genotyping of isolated $S$. aureus revealed nine spa types. Three spa types (t144, t084 and t723) of canine isolates were identified. The most prevalent of them was $t 144$, found in 8 out of the 16 isolates. In turn, $\mathrm{t} 1491(n=12)$ turned out to be the most prevalent among 15 porcine isolates, followed by t008 and t084, isolated from two and one animals, respectively. Poultry $S$. aureus isolates were represented by three types: t002 $(n=3), \mathrm{t} 127$ and $\mathrm{t} 3478(n=2$ each). The only feline isolate represented type t5447, not observed among any other animal strains (Table 1).

Phage typing revealed seven phage types representing four phage groups. The analyzed isolates belonged to three distinct phage groups (I-III), as well as to one mixed group (I + III). Phage group I was represented solely by one feline isolate (29/79/81 lytic pattern), not detected in any other host. Only canine isolates were typeable by group II phages (3C/55/71 lytic pattern). Most porcine isolates belonged to phage group III. The mixed group included canine and porcine isolates. Three poultry spa types proved to be non-typeable by phages (Table 1 ).

Toxin genes were detected in as many as 33 out of the 39 animal isolates. A total of $25 \mathrm{~S}$. aureus isolates were found to be enterotoxigenic. The sea gene, found in 12 t1491 porcine isolates and $5 \mathrm{t} 723$ canine isolates, proved to be the most frequent of classical PTSAg genes. The second most frequent PTSAg gene was sec, found in two chicken isolates representing 127 genotype. The eta gene was detected in eight canine isolates representing spa type t144. Five chicken-derived $S$. aureus isolates harbored the egcl gene grouping, comprising enterotoxin genes seg, sei, sem, sen and seo. Moreover, the $e g c l$ was carried the only one feline staphylococcal isolate. The seh gene was found solely in two t127 chicken isolates. The toxin genes were 
not harbored by any of t084 and t008 isolates. Moreover, we did not find tst and $l u k S / F-P V$ genes in our material.

\section{Discussion}

We analyzed distribution of toxin genes among spa types and phage types of animal $S$. aureus from various hosts. Better understanding of diversity of toxigenic $S$. aureus circulating in an animal reservoir adds to current knowledge on pathogenicity of $S$. aureus species.

We identified three spa types (t144, t084 and t723) among canine staphylococcal isolates. On the basis of predicted ST15, one may assume that the $\mathrm{t} 144$ and 084 isolates likely belonged to CC15 clonal complex. This complex was considered a typical human-associated lineage thus far (Sung et al. 2008). As recent studies proved that it can be presented among both human and canine isolates, a transmission of strains from humans to dogs was likely to occur (Vincze et al. 2013). The same refers to another type isolated in our study, $\mathbf{7 2 3}$, which was originally identified as a human-associated strain from a subtropical recreational marine beach (Plano et al. 2013). This points to a possible transmission of $S$. aureus isolates from humans to dogs, especially that canine isolates were typeable by group II phages. To this date, strains of phage group II were generally isolated from skin lesions in humans (Rosdahl et al. 1990; Ladhani and Joannou 2000; Piechowicz et al. 2012). They are characterized by the ability to induce skin infections, such as impetigo and staphylococcal scalded skin syndrome, associated with the synthesis of exfoliative toxins types A and B (Ladhani and Joannou 2000; Kapral and Miller 1971). Canine isolates of phage group II were the only animal staphylococci identified in our study that harbored exfoliative toxin type A (eta) gene. Previous studies showed an association between synthesis of exfoliative toxins and susceptibility to phages of group II (Parker et al. 1955; Parker and Williams 1961). This relationship, previously reported solely in the case of human $S$. aureus, was also documented among the canine isolates analyzed in our study, which may point to their potential human origin. This hypothesis is further supported by the fact that the results of recent studies suggest that incidence of $S$. aureus among dogs is associated with their contact with humans (Gomez-Sanz et al. 2013).

The only feline isolate analyzed in our study represented spa type t5447, the sequence of which closely resembled that of t3001, likely belonging to CC45 complex (http:// spaserver.ridom.de). To this date, type 5447 S. aureus was isolated from humans in Danish hospital (http://spaserver. ridom.de). Moreover, our t5447 feline isolate showed a unique lytic pattern $(29 / 79 / 81)$ corresponding to phage group I, not detected in the case of strains from any other host. The feline isolate lacked classical PTSAg genes, but contained the enterotoxin gene cluster $(e g c l)$. The egc genes were previously detected in S. aureus strains from poultry and rabbits (Bystron et al. 2010; Vancraeynest et al. 2006). Moreover, this locus was present in a number of strains isolated from healthy humans, as well as from patients with septic shock and neonates with diarrhea (Naik et al. 2008; van Belkum et al. 2006). To the best of our knowledge, our isolate is the first reported t5447 feline strain of S. aureus.

t1491 turned out to be the predominant spa type among porcine isolates. It was previously isolated from the cases of porcine infection in Denmark (Hasman et al. 2010). The two remaining spa types, t008 and t084, were previously detected in humans, dogs and cattle (Hasman et al. 2010; Vincze et al. 2013). Phage typing showed that both t1491 and t008, characterized by $75 / 84 / 85$ and 6/42/53/54 lytic patterns, respectively, belonged to phage group III. In turn, the t084 isolate represented mixed phage group (I + III). The presence of mixed phage groups among animal $S$. aureus isolates was reported previously (Vintov and Aarestrup 2003; Vintov et al. 2003). t1491 turned out to be the only isolate that harbored the sea toxin gene; the remaining two isolates were non-toxigenic. SEA is one of the first described PTSAgs (Betley and Mekalanos 1985). It constitutes the most important cause of staphylococcal food poisonings and is involved in invasive staphylococcal infections of humans (Pinchuk et al. 2010; Tristan et al. 2007). Therefore, the presence of SEA-positive isolates is associated with potential risk of food poisoning.

The presence of identified by us spa types among poultry isolates belonging to ST1 and ST5 was reported previously in various countries (Hasman et al. 2010; Ebner et al. 2013; Bystron et al. 2010; Monecke et al. 2013; Krupa et al. 2014). Recently, published Polish study revealed that $\mathrm{t} 002$ and $\mathrm{t} 3478$ were frequently isolated from the both chickens and chicken meat, indicating potential of introduction of animal-associated genotypes into food chain (Krupa et al. 2014). The staphylococci isolated from poultry were non-typeable by phages. This was likely associated with unique phenotypic and genotypic characteristics of poultry strains, distinguishing them unambiguously from their human and animal counterparts (Lowder and Fitzgerald 2010). Recently, several mobile novel elements, not found in human or animal isolates but widely distributed among poultry $S$. aureus strains, were detected (Lowder and Guinane 2009). Isolates representing ST5 showed the presence of $e g c l$, but lacked genes for other toxins. Nevertheless, egc locus was not universally harbored by all the poultry strains, as two t127 isolates showed the presence of sec and seh genes. The strains bearing the seh gene are considered a food hazard as this toxin has been unambiguously 
demonstrated as being capable of potent emetic activity (Le Loir et al. 2003).

Similar to previous studies, we did not identify animal strains of $S$. aureus harboring genes for toxic shock syndrome toxin (tst) and PV leukocidin (Gomez-Sanz et al. 2013). Therefore, such strains seem to be specific for human infections.

\section{Materials and methods}

\section{Bacterial isolates}

Between February 2008 and December 2011, 369 dogs and 33 cats were sampled at ten veterinary practices in four cities in northern Poland. One hundred and seventytwo clinically healthy dogs and twenty-one clinically healthy cats were sampled by using sterile swabs from pharynx, nares and rectum. Samples from 197 infected dogs and 12 cats (with dermatitis, external otitis, conjunctivitis, vaginitis, rhinitis and cystitis) were obtained by swabbing affected sites. Between July 2006 and February 2007, swabs were collected on four farms in northern Poland from 71 pigs with skin lesions. Poultry strains were kindly provided by Prof. Alina Wieliczko from the Department of Epizootiology with Clinic for Birds and Exotic Animals, Wroclaw University of Environmental and Life Sciences (Poland). In 2006-2008, samples from poultry with arthritis and septicemia were collected postmortem on 12 farms. Specimens were subcultured onto Columbia blood agar and incubated at $35{ }^{\circ} \mathrm{C}$ for $24 \mathrm{~h}$.

Reference enterotoxigenic S. aureus strains (F137 and F913) were kindly provided by Prof. Jacek Bania from the Wroclaw University of Environmental and Life Sciences.

\section{Identification of staphylococcal isolates}

Suspected staphylococcal isolates were identified on the basis of colony characteristics, pigment production, Gramstained appearance and hemolysis. The results were confirmed by using the API ID 32 Staph-system (bioMeriux, Poland), according to the manufacturer's instructions. In addition, all strains identified as $S$. aureus were analyzed for the presence of species-specific thermostable nuclease gene (nucSA) as described by Baron et al. (2004).

\section{Methicillin resistance detection}

DNA was isolated as described previously, and methicillin resistance was verified by $m e c A$ gene amplification (Barski et al. 1996).

\section{Presence of virulence genes}

Multiplex PCRs for the detection of exfoliative toxin genes (eta, etb) and classical staphylococcal PTSAg genes (sea, seb sec, sed, see and tst) were conducted as previously described (Mehrotra et al. 2000). The genes seg, sei, sem, sen and seo were detected according to Jarraud et al. (Jarraud et al. 2002), and the detection of seh, sej, sek, sel and sep genes followed the protocol published elsewhere (Bania et al. 2006). The amplification of PVL genes (lukS/lukF-PV) was performed as described by Lina et al. (Lina et al. 1999).

\section{Genotyping}

The spa typing was performed as described previously (Harmsen et al. 2003). Sequencing of PCR product was performed with ABI 377 device (Applied Biosystems, Foster City, California). The obtained short sequence repeats (SSRs) were numbered and processed with the Ridom SpaServer software available at http://spaserver.ridom.de.

\section{Phage typing}

Phage typing was performed using the international set of phages, as described by Blair and Williams (Blair and Williams 1961). Initially, the typing was performed at routine test dilution (RTD). Then, the strains that proved non-typeable at RTD were re-typed at $100 \times$ RTD. The strains were subdivided into phage groups I, II, III and $\mathrm{V}$, type 95, mixed group (strains belonging to different lytic groups) and NT (non-typeable at $100 \times$ RTD). The lytic patterns were determined after 18 -h incubation at $30{ }^{\circ} \mathrm{C}$.

\section{Conclusions}

Our analysis revealed that the incidence of some toxin genes in $S$. aureus is host specific. Canine isolates t144 of phage group II harbored exfoliative toxin gene (eta), and porcine isolates type $\mathrm{t} 1491$ representing phage group III showed enterotoxin A gene (sea). The enterotoxin gene cluster $(e g c l)$ and enterotoxin gene seh were found in non-typeable isolates from chicken and in one feline isolate type $\mathbf{5 4 4 7 .}$

Acknowledgments We would like to express our appreciation to Professor Alina Wieliczko from the Department of Epizootiology with Clinic for Birds and Exotic Animals, Wroclaw University of Environmental and Life Sciences (Poland), for providing poultry strains of $S$. aureus.

\section{Compliance with ethical standards}

Conflict of interest The authors declare no conflict of interest. 
Open Access This article is distributed under the terms of the Creative Commons Attribution 4.0 International License (http://creativecommons.org/licenses/by/4.0/), which permits unrestricted use, distribution, and reproduction in any medium, provided you give appropriate credit to the original author(s) and the source, provide a link to the Creative Commons license, and indicate if changes were made.

\section{References}

Bania J, Dabrowska A, Bystron J, Korzekwa K, Chrzanowska J, Molenda J (2006) Distribution of newly described enterotoxinlike genes in Staphylococcus aureus from food. Int J Food Microbiol 108:36-41

Baron F, Cochet MF, Pellerin JL, Ben Zakour N, Lebon A, Navarro A, Proudy I, Le Loir Y, Gautier M (2004) Development of a pcr test to differentiate between staphylococcus aureus and staphylococcus intermedius. J Food Prot 67:2302-2305

Barski P, Piechowicz L, Galinski J, Kur J (1996) Rapid assay for detection of methicillin-resistant Staphylococcus aureus using multiplex pcr. Mol Cell Probes 10:471-475

Betley MJ, Mekalanos JJ (1985) Staphylococcal enterotoxin a is encoded by phage. Science 229:185-187

Blair JE, Williams RE (1961) Phage typing of staphylococci. Bull World Health Organ 24:771-784

Bukowski M, Wladyka B, Dubin G (2010) Exfoliative toxins of Staphylococcus aureus. Toxins (Basel) 2:1148-1165

Bystron J, Podkowik M, Piasecki T, Wieliczko A, Molenda J, Bania J (2010) Genotypes and enterotoxin gene content of $S$. aureus isolates from poultry. Vet Microbiol 144:498-501

Devriese LA (1984) A simplified system for biotyping Staphylococcus aureus strains isolated from animal species. J Appl Bacteriol $56: 215-220$

Ebner R, Johler S, Sihto HM, Stephan R, Zweifel C (2013) Microarray-based characterization of Staphylococcus aureus isolates obtained from chicken carcasses. J Food Prot 76:1471-1474

Espinosa-Gongora C, Chrobak D, Moodley A, Bertelsen MF, Guardabassi L (2012) Occurrence and distribution of Staphylococcus aureus lineages among zoo animals. Vet Microbiol 158:228-231

Gomez-Sanz E, Torres C, Benito D, Lozano C, Zarazaga M (2013) Animal and human Staphylococcus aureus associated clonal lineages and high rate of staphylococcus pseudintermedius novel lineages in Spanish kennel dogs: predominance of $S$. aureus st398. Vet Microbiol 166:580-589

Harmsen D, Claus H, Witte W, Rothganger J, Claus H, Turnwald D, Vogel U (2003) Typing of methicillin-resistant Staphylococcus aureus in a university hospital setting by using novel software for spa repeat determination and database management. J Clin Microbiol 41:5442-5448

Hasman H, Moodley A, Guardabassi L, Stegger M, Skov RL, Aarestrup FM (2010) Spa type distribution in Staphylococcus aureus originating from pigs, cattle and poultry. Vet Microbiol 141:326-331

Jarraud S, Mougel C, Thioulouse J, Lina G, Meugnier H, Forey F, Nesme X, Etienne J, Vandenesch F (2002) Relationships between Staphylococcus aureus genetic background, virulence factors, agr groups (alleles), and human disease. Infect Immun 70:631-641

Kapral FA, Miller MM (1971) Product of Staphylococcus aureus responsible for the scalded-skin syndrome. Infect Immun 4:541-545

Krakauer T (2013) Update on staphylococcal superantigen-induced signaling pathways and therapeutic interventions. Toxins (Basel) 5:1629-1654
Krupa P, Bystroń J, Bania J, Podkowik M, Empel J, Mroczkowska A (2014) Genotypes and oxacillin resistance of Staphylococcus aureus from chicken and chicken meat in Poland. Poult Sci 93:3179-3186

Krynski S, Becla E, Pytasz Z, Malanowski J (1981) mass carrier state of Staphylococcus aureus type 187 of canine origin in a neonatal ward. Przegl Epidemiol 35:517-520

Ladhani S, Joannou CL (2000) Difficulties in diagnosis and management of the staphylococcal scalded skin syndrome. Pediatr Infect Dis J 19:819-821

Le Loir Y, Baron F, Gautier M (2003) Staphylococcus aureus and food poisoning. Genet Mol Res 2:63-76

Lina G, Piemont Y, Godail-Gamot F, Bes M, Peter MO, Gauduchon V, Vandenesch F, Etienne J (1999) Involvement of Panton-Valentine leukocidin-producing Staphylococcus aureus in primary skin infections and pneumonia. Clin Infect Dis 29:1128-1132

Lowder BV, Fitzgerald JR (2010) Human origin for avian pathogenic Staphylococcus aureus. Virulence 1:283-284

Lowder BV, Guinane CM, Ben Zakour NL, Weinert LA, ConwayMorris A, Cartwright RA, Simpson AJ, Rambaut A, Nubel U, Fitzgerald JR (2009) Recent human-to-poultry host jump, adaptation, and pandemic spread of staphylococcus aureus. Proc Natl Acad Sci USA 106:19545-19550

Mehrotra M, Wang G, Johnson WM (2000) Multiplex pcr for detection of genes for Staphylococcus aureus enterotoxins, exfoliative toxins, toxic shock syndrome toxin 1 , and methicillin resistance. J Clin Microbiol 38:1032-1035

Monecke S, Ruppelt A, Wendlandt S, Schwarz S, Slickers P, Ehricht R, Jackel SC (2013) Genotyping of Staphylococcus aureus isolates from diseased poultry. Vet Microbiol 162:806-812

Naik S, Smith F, Ho J, Croft NM, Domizio P, Price E, Sanderson IR, Meadows NJ (2008) Staphylococcal enterotoxins g and i, a cause of severe but reversible neonatal enteropathy. Clin Gastroenterol Hepatol 6:251-254

Parker MT, Williams RE (1961) Further observations on the bacteriology of impetigo and pemphigus neonatorum. Acta Paediatr 50:101-112

Parker MT, Tomlinson AJ, Williams RE (1955) Impetigo contagiosa; the association of certain types of Staphylococcus aureus and of streptococcus pyogenes with superficial skin infections. J Hyg (Lond) 53:458-473

Piechowicz L, Garbacz K, Budzynska A, Dabrowska-Szponar M (2012) Outbreak of bullous impetigo caused by Staphylococcus aureus strains of phage type $3 \mathrm{c} / 71$ in a maternity ward linked to nasal carriage of a healthcare worker. Eur J Dermatol 22:252-255

Pinchuk IV, Beswick EJ, Reyes VE (2010) Staphylococcal enterotoxins. Toxins (Basel) 2:2177-2197

Plano LR, Shibata T, Garza AC, Kish J, Fleisher JM, Sinigalliano CD, Gidley ML, Withum K, Elmir SM, Hower S et al (2013) Human-associated methicillin-resistant Staphylococcus aureus from a subtropical recreational marine beach. Microb Ecol 65:1039-1051

Rosdahl VT, Westh H, Jensen K (1990) Antibiotic susceptibility and phage-type pattern of Staphylococcus aureus strains isolated from patients in general practice compared to strains from hospitalized patients. Scand J Infect Dis 22:315-320

Sung JM, Lloyd DH, Lindsay JA (2008) Staphylococcus aureus host specificity: comparative genomics of human versus animal isolates by multi-strain microarray. Microbiology 154:1949-1959

Tristan A, Ferry T, Durand G, Dauwalder O, Bes M, Lina G, Vandenesch F, Etienne J (2007) Virulence determinants in community and hospital meticillin-resistant Staphylococcus aureus. J Hosp Infect 65(Suppl 2):105-109

van Belkum A, Melles DC, Snijders SV, van Leeuwen WB, Wertheim HF, Nouwen JL, Verbrugh HA, Etienne J (2006) Clonal 
distribution and differential occurrence of the enterotoxin gene cluster, egc, in carriage- versus bacteremia-associated isolates of Staphylococcus aureus. J Clin Microbiol 44:1555-1557

Vancraeynest D, Hermans K, Haesebrouck F (2006) Prevalence of genes encoding exfoliative toxins, leucotoxins and superantigens among high and low virulence rabbit Staphylococcus aureus strains. Vet Microbiol 117:211-218

Vincze S, Stamm I, Monecke S, Kopp PA, Semmler T, Wieler LH, Lubke-Becker A, Walther B (2013) Molecular analysis of human and canine Staphylococcus aureus strains reveals distinct extended-host-spectrum genotypes independent of their methicillin resistance. Appl Environ Microbiol 79:655-662

Vintov J, Aarestrup FM, Elsberg Zinn C, Olsen JE (2003a) Phage types and antimicrobial resistance among Danish bovine Staphylococcus aureus isolates since the 1950s. Vet Microbiol 97:63-72

Vintov J, Aarestrup FM, Zinn CE, Olsen JE (2003b) Association between phage types and antimicrobial resistance among bovine Staphylococcus aureus from 10 countries. Vet Microbiol 95:133-147 